\title{
APLIKASI PEMESANAN TIKET TRAVEL BERBASIS ANDROID MENGGUNAKAN METODE WATERFALL
}

\author{
Baharudin Maulana Misbah, Deni Murdiani \\ STMIK Muhammadiyah Jakarta, Indonesia \\ Email: Baharudinmaulana78@gmail.com,Denimurdiani@gmail.com
}

\begin{abstract}
Sadam Jaya Travel is a company engaged in transportation, namely travel between provinces in Java Island. So far the service of purchasing travel tickets by prospective passengers is still conventional, which is only limited to booking services via SMS or phone directly to the driver or kernet. This condition raises the problem of often forgetting the driver to pick up prospective support so that there are often complaints by prospective passengers. Therefore, a system is needed that can manage prospective passengers who book tickets to be recorded. In this research I intend to design the Sadam Jaya Travel application in the hope that the problems that have arisen can be resolved properly. The application development methodology that the author uses is a waterfall process with stages of analysis, design, implementation, testing, maintenance. The results of this study resulted in the Sadam Jaya Travel application using Android Studio with Kotlin and Firebase languages as a database and can be implemented properly using the Waterfall method and resulting in 100\% accepted testing.
\end{abstract}

Keyword: Application; Information; Travel Ticket Booking

\begin{abstract}
Abstrak
Travel Sadam Jaya adalah perusahaan yang bergerak di bidang transportasi yaitu travel perjalanan antar provinsi di Pulau Jawa. Selama ini pelayanan pembelian tiket perjalanan oleh calon penumpang masih konvensional yaitu baru sebatas layanan pemesanan via SMS atau telepon langsung ke supir atau kernet. Kondisi tersebut memunculkan masalah sering lupanya supir untuk menjemput calon penunpang sehingga sering terjadi komplain oleh pihak calon penumpang. Oleh karena itu dibutuhkan sebuah sistem yang dapat mengelola calon penumpang yang memesan tiket agar tercatat. Dalam penelitian ini saya bermaksud untuk merancang aplikasi Travel Sadam Jaya dengan harapan masalah yang selama ini muncul dapat teratasi dengan baik. Metodologi pengembangan aplikasi yang penulis gunakan adalah proses waterfall dengan tahapan analisis, desain, implementasi, testing, maintanence. Hasil penelitian ini menghasilkan aplikasi Travel Sadam Jaya menggunakan Android Studio dengan bahasa Kotlin dan Firebase sebagai database dan dapat diimplementasikan dengan baik menggunakan metode Waterfall dan menghasilkan pengujian yang $100 \%$ diterima.
\end{abstract}

Kata Kunci: Aplikasi; Informasi; Pemesanan Tiket Travel. 


\section{Pendahuluan}

Teknologi informasi saat ini sudah sangat berkembang dan terus berkembang seiring berjalannya waktu, munculnya berbagai jenis aplikasi memiliki pilihan untuk mempermudah pekerjaan. hingga saat ini muncul banyak sekali aplikasi baru yang berjalan dalam mobile seperti perangkat android saat ini, yang mana selain lebih mudah pengoperasiannya, perangkat mobile juga lebih fleksibel (Marimin, 2004).

Penggunaan Aplikasi android di Travel Sadam Jaya akan lebih memudahkan para calon penumpang untuk melakukan booking dan juga memperluas pangsa penumpang Travel Sadam Jaya karena akses menggunakan ponsel android dan akan lebih mudah (Darsono, 2005).

Travel Sadam Jaya berada di desa Sugihan, Kabupaten Wonogiri. Usaha Travel ini berdiri 3 tahun yang lalu. Travel Sadam Jaya biasa mendapat penumpang hanya dari masyarakat sekitar yang mengenal dan mengetahuinya saja, yang hanya tersebar dari mulut ke mulut, serta proses pemesannya juga terkesan masih sederhana dikarenakan pemesanan dilakukan masih menggunakan via sms atau telepon dan kendala yang biasa terjadi saat pemesanan adalah supir sering lupa melakukan penjemputan (Pramono et al., 2020).

Pemakaian Aplikasi Booking Travel Sadam Jaya akan memudahkan proses booking dan juga memudahkan mendapatkan penumpang lebih luas lagi. Berdasarkan kendala dan uraian di atas maka penulisan dapat membuat judul: Aplikasi Pemesanan Tiket Travel Berbasis Android Menggunakan Metode Waterfall. Sebelumnya sudah penelitian yang dilakukan oleh Bimo Fantri pada Travel Bimo Trans, hanya saja berbeda objek dan metode penelitian (Fantri Setiarko, 2016).

\section{Metode Penelitian}

\section{Tempat dan Waktu Penelitian}

Dalam menentukan objek penelitian, penulis melakukan penelitian di Travel Sadam Jaya yang terletak di dusun Sumber Agung Desa Sugihan, Kecamatan Jatiroto, Kabupaten Wonogiri Provinsi Jawa Tengah, 57692. Adapun waktu yang diperlukan dalam menyelesaikan penelitian ini, dengan rincian tabel sebagai berikut :

Tabel 1. Rencana Kerja penelitian 


\begin{tabular}{|c|c|c|c|c|c|c|c|c|c|c|c|c|c|c|c|c|}
\hline \multirow[b]{2}{*}{ NO } & \multirow[b]{2}{*}{ KEGIATAN } & \multicolumn{3}{|c|}{ April } & \multicolumn{4}{|c|}{ Mei } & \multicolumn{4}{|c|}{ Juni } & \multicolumn{4}{|c|}{ Juli } \\
\hline & & \begin{tabular}{|l|l|} 
I & II \\
\end{tabular} & \begin{tabular}{|l|l|} 
III \\
\end{tabular} & IV & I & III & IIII & IV & & III & III & IV & & II & III & IV \\
\hline 1 & $\begin{array}{l}\text { Perancangan } \\
\text { judul }\end{array}$ & & & & & & & & & & & & & & & \\
\hline 2 & $\begin{array}{l}\text { Bimbinngan } \\
\text { dan Revisi }\end{array}$ & & & & & & & & & & & & & & & \\
\hline 3 & \begin{tabular}{|c|} 
Pengumpula \\
n dan analisa \\
w data
\end{tabular} & & & & & & & & & & & & & & & \\
\hline 4 & $\begin{array}{l}\text { Rancang } \\
\text { Bangun } \\
\text { Program }\end{array}$ & & & & & & & & & & & & & & & \\
\hline
\end{tabular}

\section{Teknik pengumpulan data}

Teknik pengumpulan data yang digunakan pada penelitian ini adalah:

1. Observasi

Teknik observasi digunakan untuk mengumpulkan data yang berkaitan dengan aspek

functionality, dan portability.

2. Kuesioner

Teknik kuesioner digunakan untuk mengumpulkan data yang berkaitan dengan aspek

usability

\section{Metode Penelitian}

Penelitian ini menggunakan metode penelitian Research and Development atau yang disingkat $\mathrm{R} \& \mathrm{D}$, sesuai dengan namanya penelitian ini berisi mengenai research atau penelitian dan development atau pengembangan. Tahapan research digunakan untuk mendapatkan analisis lebih lanjut dari suatu masalah dan mendefinisikan masalah sehingga menghasilkan gambaran atau desain. Sedangkan tahapan kedua yakni development atau pengembangan merupakan implementasi dari gambaran atau desain yang sudah dibuat dari hasil penelitian (Santoso \& Handojo, 2014).

\section{Metodologi Pengembangan Perangkat Lunak}

Metode pengembangan sistem yang digunakan dalam penelitian ini adalah metode pengembangan sistem waterfall. Metode pengembangan model waterfall atau yang sering disebut metode air terjun sering dinamakan siklus hidup klasik (classic life cycle), dimana hal ini menggambarkan pendekatan yang sistematis dan juga berurutan pada pengembangan perangkat lunak, dimulai dengan spesifikasi kebutuhan pengguna lalu berlanjut melalui tahapan-tahapan perencanaan (planning), pemodelan (modeling), konstruksi (construction), serta penyerahan sistem ke para pelanggan/pengguna (deployment), yang diakhiri dengan dukungan pada perangkat lunak lengkap yang dihasilkan (Abdurrahman \& Masripah, 2017). 


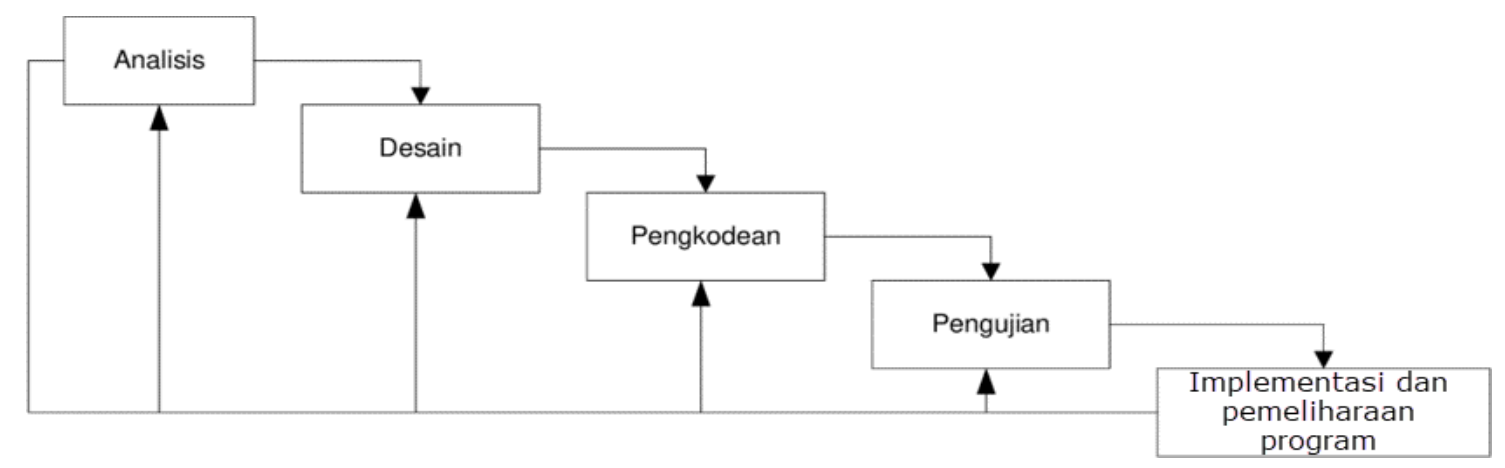

Gambar 2. Model waterfall menurut Pressman

\section{Hasil dan Pembahasan}

\section{Analisa kebutuhan perangkat keras}

Adapun kebutuhan minimum dan yang disarankan untuk menggunakan aplikasi Pemesanan Tiket Travel adalah sebagai berikut:

Tabel 1 Kebutuhan perangkat keras (Hardware)

\begin{tabular}{lll}
\hline \multicolumn{1}{c}{ Perangkat Keras } & \multicolumn{1}{c}{ Kebutuhan Minimum } & Kebutuhan Yang Disarankan \\
\hline Processor & 1.2 Gigahertz $(\mathrm{GHz})$ & Diatas 1.2 Gigahertz $(\mathrm{GHz})$ \\
\hline Memori RAM & $8 \mathrm{gb}$ & $16 \mathrm{gb}$ atau lebih \\
\hline Harddisk & $100 \mathrm{gb}$ & $256 \mathrm{gb}$ atau lebih \\
\hline Keyboard & Standar & Standar \\
\hline Moused & Standar & Standar \\
\hline
\end{tabular}

\section{Analisa kebutuhan perangkat lunak}

Adapun perangkat lunak untuk membangun program ini adalah sebagai berikut:

Tabel 2. Kebutuhan perangkat lunak (Software)

\begin{tabular}{ll}
\hline \multicolumn{1}{c}{ Perangkat Lunak } & \multicolumn{1}{c}{ Keterangan } \\
\hline Ubuntu 20.04 LTS & Sebagai Sistem Operasi \\
\hline Kotlin & Sebagai Bahasa Pemrograman \\
\hline Firebase & Sebagai Pembuatan Database \\
\hline Android Studio & Sebagai Editor Program \\
\hline
\end{tabular}

\section{Analisa Sistem Yang Berjalan}

Berdasarkan analisa sistem yang berjalan dilakukan pada Travel Sadam Jaya, proses pemesanan masih manual melalui pesan singkat biasa. Untuk mengetahui mengenai prosedur sistem yang berjalan saat ini: 


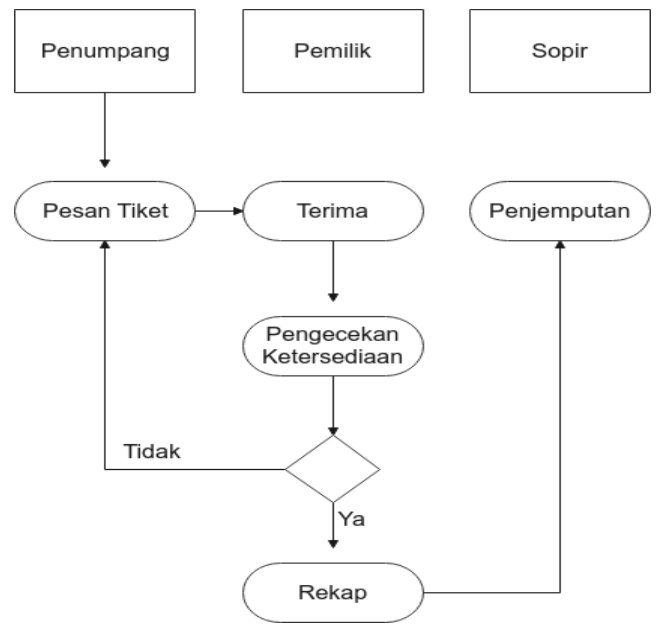

Gambar 3 Aktivitas Diagram Sistem Yang Berjalan

\section{Sistem Yang Diusulkan}

Adapun analisa sistem yang diusulkan juga dipresentasikan dalam bentuk diagram actifity sebagai berikut:

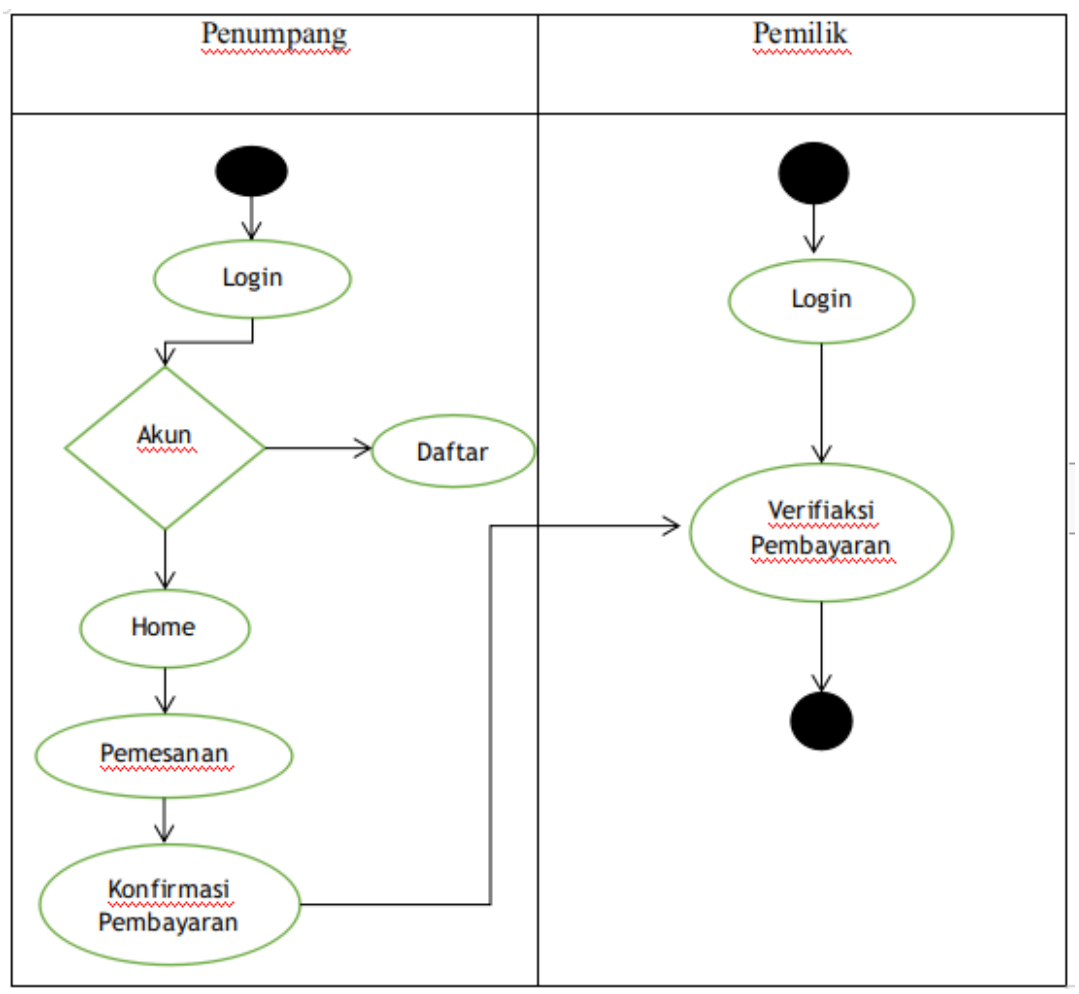

Gambar 4 Aktivitas Diagram Sistem Yang Diusulkan

Pada analisa diatas ketika penumpang akan melakukan pemesanan tiket maka diharuskan untuk login dan mendaftar jika belum mempunyai akun. Ketika sudah dilakukannya pemesanan maka pemilik akan melakukan verifikasi tiket (Pratama, Tasrif, \& Hadi, 2017).

\section{Implementasi}

a. Tampilan Halaman Login 
Halaman ini berisi form untuk melakukan login dan juga ada tombol untuk mendaftar apabila belum mempunyai akun.

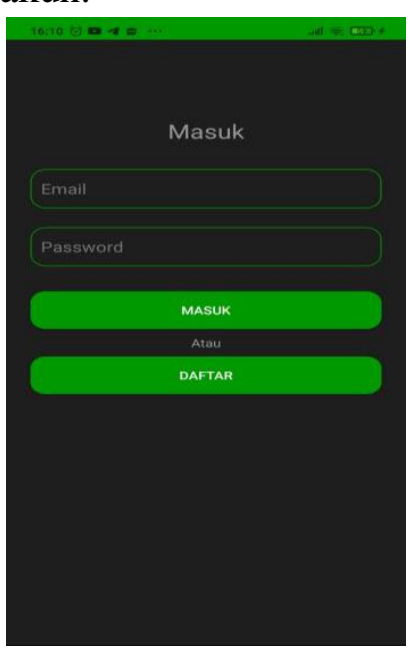

Gambar 5. Tampilan Menu Login.

\section{b. Tampilan Halaman Penumpang}

Halaman utama aplikasi pemesanan tiket di Travel Sadam Jaya ketika sudah melakukan login atau daftar.

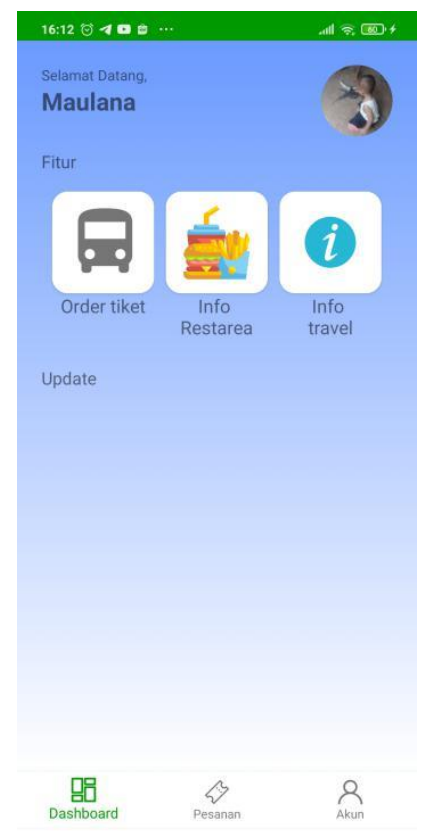

Gambar 6. Tampilan Menu Home Penumpang

\section{c. Tampilan Pemesanan Tiket}

Halaman ini berisi tentang alamat penjemputan, alamat tujuan, dan tanggal keberangkatan. 
Baharudin Maulana Misbah, Deni Murdiani

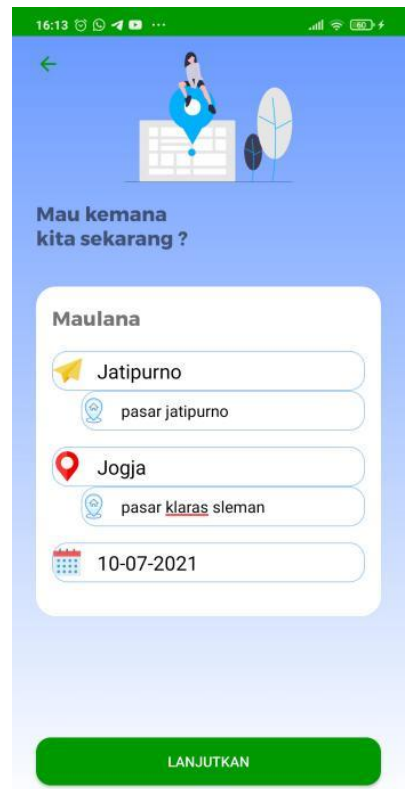

Gambar 7. Tampilan Pemesanan Tiket

\section{d. Tampilan Halaman Travel}

Halaman ini berisi daftar travel yang akan menuju ke tujuan masing masing sesuai dengan pilihan pelanggan.

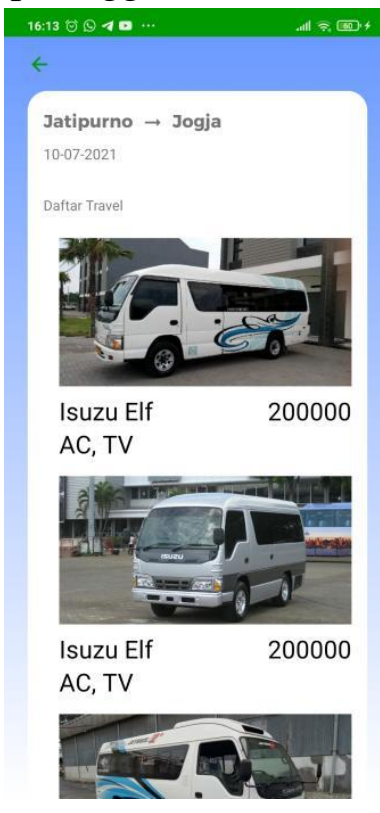

Gambar 8. Tampilan Halaman Travel

\section{e. Tampilan Halaman Pemilihan Kursi}

Halaman ini penumpang akan memilih posisi kursi yang di inginkanya dan juga bisa memilih dua atau tiga tempat. 


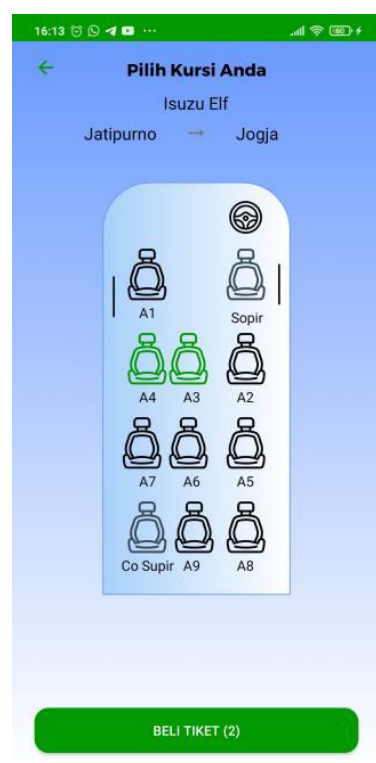

\section{f. Tampilan Halaman Pembayaran}

Gambar 9. Tampilan Pemilihan Kursi

Menu ini menampilkan detail singkat mengenai tujuan dan tanggal keberangkatan dan juga ditampilkan harga yang harus dibayar serta nomor rekening pemilik travel.

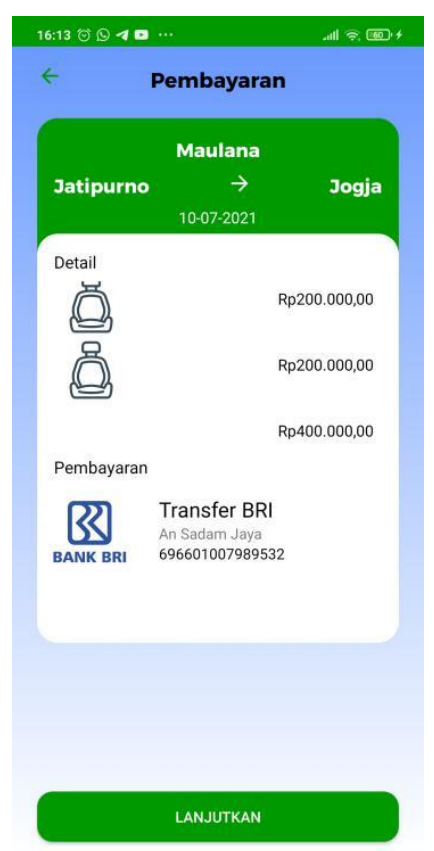

Gambar 10. Tampilan Halaman Pembayaran

\section{g. Tampilan Halaman Upload Bukti Pembayaran}

Penumpang diharuskan untuk melakukan transfer ke nomor rekening yang telah disediakan di halaman sebelumnya dan segera mengupload bukti pembayaran kepada pemilik agar dapat diverifikasi. 
Baharudin Maulana Misbah, Deni Murdiani

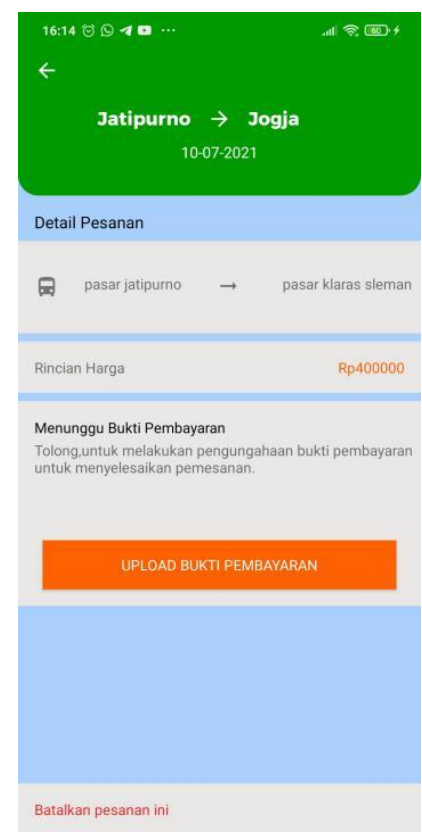

Gambar 11. Tampilan Halaman Upload Bukti Pembayaran

\section{h. Tampilan Halaman Tiket Terverifikasi}

Jika penumpang telah mengunggah foto bukti pembayaran kepada pemilik, maka pemilik akan melakukan verifikasi terhadap tiket penumpang.

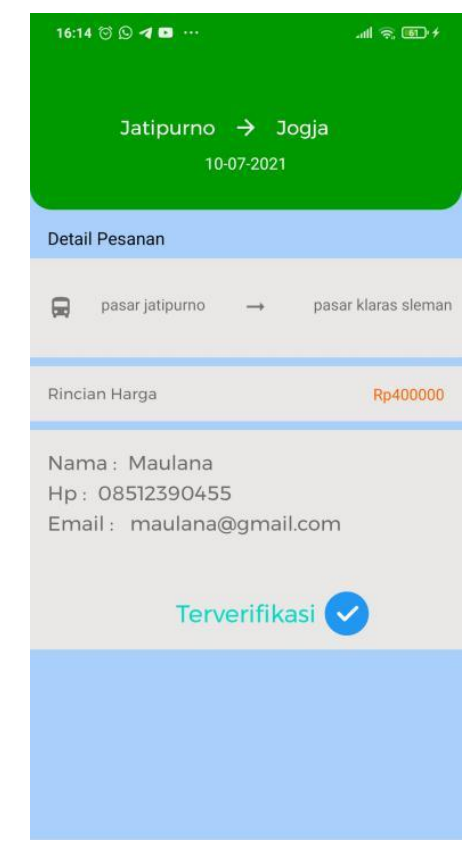

\section{Pengujian}

Gambar 12. Tampilan Halaman Tiket Telah Terverifikasi

Pengujian dilakukan untuk mengetahui apakah fungsi yang telah dibuat berjalan sesuai dengan yang diinginkan.

\section{a. Rencana Pengujian}

Tabel 3. Rencana Pengujian 


\begin{tabular}{|c|l|l|}
\hline No & \multicolumn{1}{|c|}{ Item Uji } & \multicolumn{1}{c|}{ Jenis Pengujian } \\
\hline 1 & Login & Black Box \\
\hline 2 & Registrasi & Black Box \\
\hline 3 & Input Tujuan & Black Box \\
\hline 4 & Konfirmasi Pembayaran & Black Box \\
\hline 5 & Verifikasi Tiket & Black Box \\
\hline
\end{tabular}

\section{b. Hasil Pengujian}

Tabel 4. Hasil Uji Login

\begin{tabular}{lcc}
\hline \multicolumn{1}{c}{ Skenario } & Hasil Uji & \\
\hline $\begin{array}{l}\text { Input Username dan password } \\
\text { sesuai yang terdaftar di } \\
\text { database }\end{array}$ & Muncul ke menu Dashboard & Login \\
\hline \multicolumn{2}{c}{ Tabel 5. Hasil Uji Registrasi } \\
(Berhasil) \\
\hline \multicolumn{1}{c}{ Skenario } & Hasil Uji & \\
\hline $\begin{array}{l}\text { Klik Tombol Registrasi pada } \\
\text { form register }\end{array}$ & Kesimpulan & Hasil \\
\hline
\end{tabular}

Tabel 6. Hasil Uji Input Tujuan

\begin{tabular}{lcc}
\hline \multicolumn{1}{c}{ Hasil Uji } \\
\hline \multicolumn{1}{c}{ Skenario } & Kesimpulan & Hasil \\
\hline $\begin{array}{l}\text { Klik Tombol lanjutkan dengan } \\
\text { sudah mengisi semua form } \\
\text { yang tersedia }\end{array}$ & Menampilkan Daftar Travel & Input Tujuan \\
(Berhasil)
\end{tabular}

Tabel 7. Hasil Uji Konfirmasi Pembayaran

\begin{tabular}{llc}
\hline \multicolumn{1}{c}{ Skenario } & \multicolumn{1}{c}{ Hasil Uji } \\
\hline \multicolumn{1}{c}{ Kesimpulan } & Hasil \\
pembayaran & Muncul pesan karena tidak ada & Konfirmasi \\
& aplikasi whatsapp & Pembayaran \\
& & (Berhasil) \\
\hline
\end{tabular}

Tabel 8. Hasil Uji Verifikasi Tiket

\begin{tabular}{ccc}
\hline & Hasil Uji & \\
\hline Skenario & Kesimpulan & Hasil \\
\hline Klik tombol verifikasi tiket & Muncul di data tiket & Verifikasi Tiket \\
\hline
\end{tabular}




\section{Pemeliharaan Program (Maintenance)}

Pemeliharaan Sistem ini dilakukan agar sistem berjalan dengan baik.

Pemeliharaan ini mencakup pemeliharaan software dan hardware secara teratur (Muslihudin, 2016). Pemeliharaan sistem ini berguna untuk menghindari masalahmasalah yang muncul saat menjalankan aplikasi.

1.Pemeliharaan perangkat lunak

Update Software ini bertujuan agar aplikasi berjalan dengan optimal dengan kode-kode yang diperbaharui dan juga data-data yang baru, serta untuk menambahkan fitur baru.

2.Pemeliharaan perangkat keras

a. Isi Baterai HP ketika sudah melemah.

b. Jauhkan dari air.

c. Jangan diletakkan ditempat yang panas.

\section{Kesimpulan}

Perancangan sistem Travel Sadam Jaya menggunakan Android Studio dengan bahasa Kotlin dan Firebase sebagai database sudah dapat diimplementasikan dengan baik menggunakan metode Waterfall. Dari hasil pengujian terhadap 5 item menggunakan tool black box diperoleh hasil $100 \%$ diterima, diantaranya pengujian login, registrasi, input tujuan, konfirmasi pembayaran, verifikasi tiket. 


\section{BIBLIOGRAFI}

Abdurrahman, Asep, \& Masripah, Siti. (2017). Metode Waterfall Untuk Sistem Informasi Penjualan. Information System For Educators And Professionals: Journal of Information System, 2(1), 95-104. Google Scholar

Darsono, M. B. A. (2005). Ashari. Pedoman Praktis Memahami Laporan Keuangan. Yogyakarta: Adni. Google Scholar

Fantri Setiarko, Bimo. (2016). Aplikasi Pemesanan Tiket Travel Berbasis Mobile Android Pada Bimo Trans. Universitas Komputer Indonesia. Google Scholar

Marimin, Marimin. (2004). Teknik dan Aplikasi Pengambilan Keputusan Kriteria Majemuk. PT. Grasindo, Jakarta. Google Scholar

Muslihudin, Muhamad. (2016). Analisis Dan Perancangan Sistem Informasi Menggunakan Model Terstruktur Dan UML. Penerbit Andi. Google Scholar

Pramono, Rudy, Winda, Yolenta, Purwanto, Agus, Prameswari, Mirza, Asbari, Masduki, \& Purba, Rosma Indriana. (2020). Narrative Study: The Life of Influencers between Hobbies and Professions. International Journal of Advanced Science and Technology, 29(3), 8417-8438. Google Scholar

Pratama, Hanif Efriko, Tasrif, Elfi, \& Hadi, Ahmadul. (2017). Sistem Informasi Penyewaan dan Pemesanan Tiket Bus dan Travel Kota Padang. Voteteknika (Vocational Teknik Elektronika Dan Informatika), 5(2). Google Scholar

Santoso, Agus, \& Handojo, Andreas. (2014). Pembuatan Aplikasi Mobile Broadcast Informasi Perkuliahan Berbasis Android. Jurnal Infra, 2(1), 104-109. Google Scholar

First publication right:

Jurnal Syntax Fusion: Jurnal Nasional Indonesia

This article is licensed under:

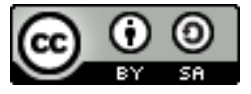

